November 2004 - NREL/CP-500-36891

\title{
Analysis and Comparison of Test Results from the Small Wind Research Turbine Test Project
}

\section{Preprint}

\author{
D. Corbus and D. Prascher
}

To be presented at the $43^{\text {rd }}$ AIAA Aerospace Sciences Meeting and Exhibit

Reno, Nevada

January 10-13, 2005

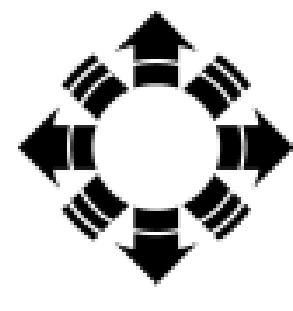

\section{NPEI}

National Renewable Energy Laboratory 1617 Cole Boulevard, Golden, Colorado 80401-3393 303-275-3000 • www.nrel.gov

Operated for the U.S. Department of Energy

Office of Energy Efficiency and Renewable Energy

by Midwest Research Institute $\bullet$ Battelle 


\section{NOTICE}

The submitted manuscript has been offered by an employee of the Midwest Research Institute (MRI), a contractor of the US Government under Contract No. DE-AC36-99G010337. Accordingly, the US Government and MRI retain a nonexclusive royalty-free license to publish or reproduce the published form of this contribution, or allow others to do so, for US Government purposes.

This report was prepared as an account of work sponsored by an agency of the United States government. Neither the United States government nor any agency thereof, nor any of their employees, makes any warranty, express or implied, or assumes any legal liability or responsibility for the accuracy, completeness, or usefulness of any information, apparatus, product, or process disclosed, or represents that its use would not infringe privately owned rights. Reference herein to any specific commercial product, process, or service by trade name, trademark, manufacturer, or otherwise does not necessarily constitute or imply its endorsement, recommendation, or favoring by the United States government or any agency thereof. The views and opinions of authors expressed herein do not necessarily state or reflect those of the United States government or any agency thereof.

Available electronically at http://www.osti.gov/bridge

Available for a processing fee to U.S. Department of Energy and its contractors, in paper, from:

U.S. Department of Energy

Office of Scientific and Technical Information

P.O. Box 62

Oak Ridge, TN 37831-0062

phone: 865.576 .8401

fax: 865.576 .5728

email: mailto:reports@adonis.osti.gov

Available for sale to the public, in paper, from:

U.S. Department of Commerce

National Technical Information Service

5285 Port Royal Road

Springfield, VA 22161

phone: 800.553 .6847

fax: 703.605.6900

email: orders@ntis.fedworld.gov

online ordering: http://www.ntis.gov/ordering.htm 


\title{
Analysis and Comparison of Test Results from the Small Wind Research Turbine Test Project
}

\author{
David Corbus ${ }^{*}$ and Dan Prascher ${ }^{\dagger}$ \\ National Renewable Energy Laboratory, Golden, Colorado 80401
}

\begin{abstract}
Most small wind turbines furl (yaw or tilt out of the wind) as a means of limiting power and rotor speeds in high winds. The Small Wind Research Turbine (SWRT) testing project was initiated in 2003 with the goal of better characterizing both small wind turbine loads (including thrust) and dynamic behavior, specifically as they relate to furling. The main purpose of the testing was to produce high-quality data sets for model development and validation and to help the wind industry further their understanding of small wind turbine behavior. Testing was conducted on a modified Bergey Excel 10-kW wind turbine. A special shaft sensor was designed to measure shaft loads including thrust, torque, and shaft bending. Analysis of 10-minute mean data showed a strong correlation between furling and center of thrust location, as calculated from the shaft-bending and thrust measurements. Data were collected for three different turbine configurations that included a change in the lateral furling offset and the blades. An analysis of inflow conditions indicated that organized atmospheric turbulence had some impact on furling.
\end{abstract}

\section{Introduction}

M any small wind turbines use furling, whereby the rotor either tilts and/or yaws out of the wind, to protect from overspeed and over-power during excessive winds. In the past, most small wind turbine designers used trialand-error approaches, often using variable geometry test platforms to vary furling offsets. Recent upgrades in the FAST and ADAMS with AeroDyn wind turbine areoelastic simulation models [1] have incorporated furling into the models. FAST's new furling-related features include a lateral offset and skew angle of the rotor shaft, rotor- and tailfurling degrees-of-freedom, up- and down-furl stops, and tail fin aerodynamics and inertia $[2,3]$. However, to date there has been a limited amount of test data available for model validation of small furling wind turbines [4]. Acquiring good test data for a small furling wind turbine was a recommended action of the National Wind Technology Center (NWTC) Furling Workshop held in July of 2000 [5] and has been mentioned in previous papers on furling [6]. The Small Wind Research Turbine (SWRT) project was initiated to provide reliable test data for model validation of furling wind turbines and to help understand small wind turbine loads. The measurements of thrust and furling are of particular importance to the model validation effort and are unique to this test.

\section{Experiment Overview}

\section{A. Test Turbine}

The SWRT is a modified Bergey EXCEL 10-kW turbine that furls horizontally out of the wind. The rotor/generator/main-frame assembly is connected to a tail boom at a furling pivot joint by a pin connection. The axis of the furling pivot joint is inclined laterally at a small angle to the vertical yaw axis and produces a gravity restoring moment. A main frame stop keeps the tail boom from furling more than about 68 degrees. There is a lateral offset between the yaw axis and the rotor axis. As the wind speed increases, so does the thrust and the aerodynamic normal force on the nominally aligned vertical tail at the end of the tail boom. Furling occurs when the rotor moments exceed the gravity restoring moment. The furl damper provides very little resistance to furling but a high resistance to unfurling.

The Bergey EXCEL is a three-bladed upwind turbine rated at $10-\mathrm{kW}$ output at $13.0 \mathrm{~m} / \mathrm{s}$. The EXCEL uses a permanent magnet alternator to produce three-phase variable frequency output at a nominal 240 -volts. Inside the Gridtek inverter, the three-phase output is rectified to DC power and then converted to single-phase 240-volt 60-hz $\mathrm{AC}$ power. The turbine blades are constant chord and made from pultruded fiberglass, and the direction of rotation is

\footnotetext{
* Senior Mechanical Engineer, National Wind Technology Center, MS3811, AIAA Member.

${ }^{\dagger}$ Student Intern, National Wind Technology Center, MS3811.

This paper is declared a work of the U.S. Government and is not subject to copyright protection in the United States.
} 
counter-clockwise when looking downwind. The turbine shaft has an 8-degree tilt, and the turbine is mounted on a Rohn SSV, 24.4-m (80-ft), freestanding lattice tower. The turbine was modified in several ways to allow for test instrumentation to be installed. One significant modification was that the turbine main shaft was shortened approximately $0.18 \mathrm{~m}$ (7 in.) to allow for installation of a $0.18-\mathrm{m}$ (7-in.) load fixture, in line with the non-rotating shaft, to measure shaft loads. Other modifications include changes to the weight of the turbine from the DAS components and changes to the blade length.

The SWRT test is located at the NWTC as shown in Fig. 1. The turbine was installed in May of 2003, and preliminary testing was conducted until January of 2004. The testing for the data sets described in this paper began in January of 2004 and concluded in June of 2004.

It should be noted that the SWRT is modified from the commercial Bergey EXCEL turbine and that the test results in this paper are not necessarily representative of the Bergey EXCEL turbine.

\section{B. Measured Parameters}

Table 1 lists the measured parameters for the test. Of particular importance is the shaft load fixture that was built specifically for the test to measure thrust, shaft 0 and 90 -degree bending, and torque. Fig. 2 depicts the shaft load fixture, opened up to show the four strain-gaged posts that carry all of the rotor loads. The shaft sensor is located on the non-rotating shaft at approximately $0.51 \mathrm{~m}$ (20.35 in.) from the rotor center.

Flap and edge signals are measured on all blades and then amplified (50x and 166x, respectively) on the data acquisition system (DAS) where they are digitized. A sonic anemometer is located at hub height at a distance of $19.8 \mathrm{~m}(64.9 \mathrm{ft})$ upwind from the turbine, which is 3.4 rotor diameters. A sonic anemometer is also located on the tail of the turbine just upwind of the tail fin. $\mathrm{AC}$ variablevoltage power is measured at the output of the turbine upstream of the inverter.

\section{Data Acquisition System}

The data acquisition system used is Zond's Advanced Data Acquisition System (ADAS), which is a distributed multi-source, synchronous, multi-channel data recorder. By employing remote Data Acquisition Modules (DAMs), the ADAS records data near the source of the measurement. A PC-based computer

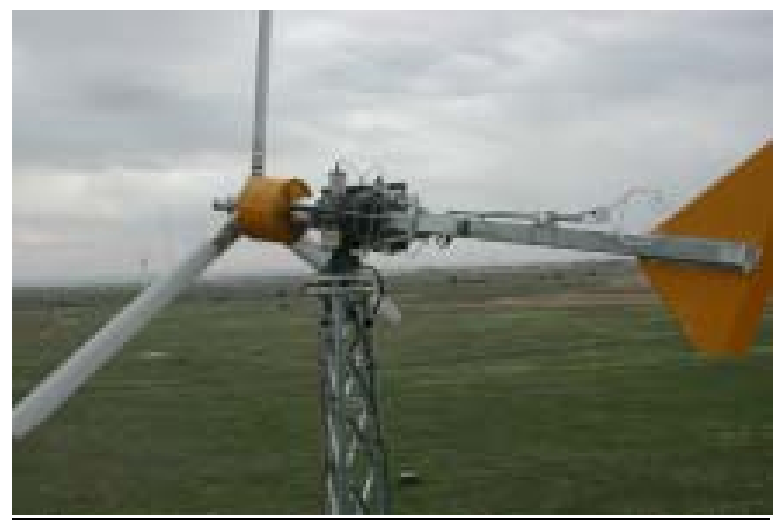

Figure 1. SWRT at the National Wind Technology Center.

Table 1. Measured parameters and sensor list.

\begin{tabular}{|l|l|}
\hline \multicolumn{1}{|c|}{ Parameter Measured } & \multicolumn{1}{|c|}{ Sensor Type } \\
\hline $\begin{array}{l}\text { Flap and edge bending } \\
\text { all three blades }\end{array}$ & Full bridge strain gage \\
\hline $\begin{array}{l}\text { Shaft thrust, 0/90 degree } \\
\text { bending, and torque }\end{array}$ & $\begin{array}{l}\text { Full bridge strain gage } \\
\text { on load-fixture }\end{array}$ \\
\hline Shaft RPM and position & Encoder \\
\hline Yaw position and rate & Encoder \\
\hline Wind speed/direction & Sonic anemometer \\
\hline Tail wind speed/direction & Sonic anemometer \\
\hline Power from turbine & Watt transducer \\
\hline Tower top bending & $\begin{array}{l}\text { Load cell on each tower } \\
\text { top leg }\end{array}$ \\
\hline Furl & $\begin{array}{l}\text { Rotary Variable } \\
\text { Inductance Transducer }\end{array}$ \\
\hline $\begin{array}{l}\text { Mid-tower and 3-m wind } \\
\text { speed }\end{array}$ & Mechanical anemometer \\
\hline Temperature & Temperature transducer \\
\hline Pressure & Pressure transducer \\
\hline
\end{tabular}

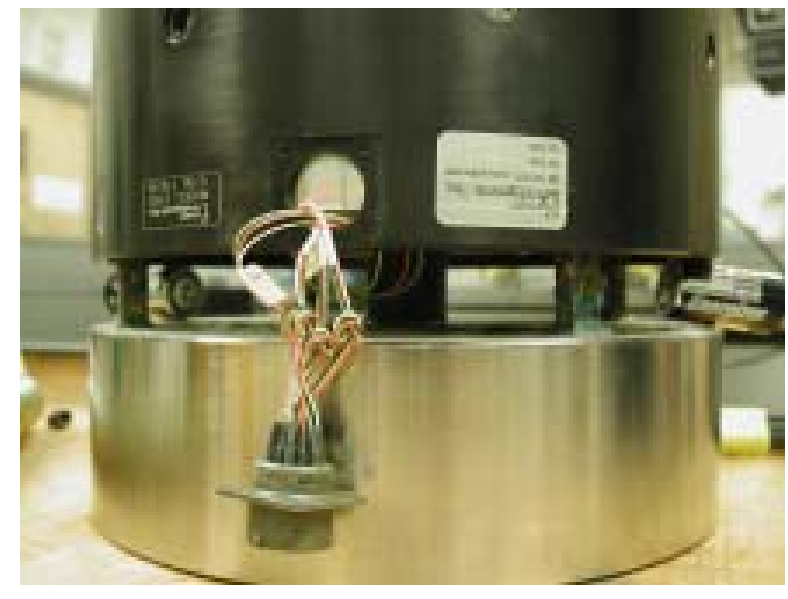

Figure 2. Shaft load fixture. 
system acts as the host, performing all set-up, programming, data display, and downloading duties. All channels are synchronized, and data acquisition occurs simultaneously without multiplexing. Data are sampled at $160 \mathrm{hz}$, and a 40-hz, 6-pole low-pass Butterworth filter is used to filter the data. Records of 10 minutes in length are stored.

\section{Pre-Test Turbine Characterization}

To supply inputs for aeroelastic models of the SWRT, the turbine tail assembly and main frame were weighed and center of gravities (Cgs) were determined. Tests were also conducted to calculate the moment of inertia about the tail axis and the yaw axis. Tail damper properties were measured and all turbine geometries noted. A modal test was conducted for a blade to determine mode shapes and frequencies for flap and edge.

\section{E. Calculated Parameters}

Calculated channels were used for a wide range of parameters based on the measured data. Calibrations were performed for flap and edge bending on the blades, and the results were used to calculate the 2-by-2 crosstalk matrix for blade flap and edge-bending moments. The shaft sensor was calibrated by the manufacturer, Sensor Developments, and the A2LA-accredited calibration was confirmed at the NWTC in a special test rig with the turbine mounted on the upper tower section in a high bay. The results of the Sensor Development calibration were used to calculate the four-by-four crosstalk matrix for shaft thrust, 0 - and 90-degree bending moments, and torque. A post-test calibration conducted by Sensor Developments verified that the sensor stayed in calibration during the test.

\section{Turbine Testing}

\section{A. Turbine Configurations}

Data were collected for three turbine configurations, A, B, and C, as summarized in Table 2. Configuration A and $\mathrm{B}$ differ by the lateral offset distance between the rotor centerline and the yaw axis, which is $0.106 \mathrm{~m}$ in Configuration A and $0.083 \mathrm{~m}$ in Configuration B (a 22\% change). The change in the lateral offset for Configuration A was implemented by placing a 4-degree shim between the alternator and the shaft sensor. Configuration $\mathrm{C}$ has a greater swept area (about 20\%) than Configurations A and $\mathrm{B}$ and different blade pitch, and it is representative of the current version of the Bergey EXCEL turbine blades.

In addition to all configurations running with a shaft tilt of 8 degrees, all three turbine configurations ran at an average yaw error of between 13 and 23 degrees, resulting in a significant skewed wake.

A total of 514 10-minute records were collected, 200 for configuration A, 78 for B, and 236 for configuration C. An additional 248 2-minute record data sets were collected for configuration B prior to Table 2. SWRT configurations. the 10-minute data sets and were used for data verification during turbine start up.

The number of test records for each configuration was affected by unexpected test results. For example, the test started with the SH3052 blades without a shim as the baseline configuration, but the turbine did not furl at a lowenough wind speed, and the inverter went off-line from high-power or voltage faults. A 2-degree, then a 4-degree, lateral shim was introduced to try to prevent these fault conditions by getting the turbine to furl at lower wind speeds and, hence, prevent over-power conditions. However, this did not prevent the faults, as the turbine would not always furl fast enough in high wind conditions. The inverter torque-RPM curve in the software was finally changed to minimize the inverter faults, but some data with high wind speed inverter faults needed to be excluded from the final data sets. Another drawback to the inverter controller for this experimental testing was that it would unload the turbine in very low winds so data sets below $5 \mathrm{~m} / \mathrm{s}$ were missing, which is not important for furling data but can be important for characterizing turbine operation. All final configurations were run with the same inverter torque-RPM curve.

The change to a new blade configuration was prematurely introduced into the test matrix because the strain gages for the flap signals on the first set of blades reached the rated cycle life of between $10^{6}$ and $10^{7}$. cycles. The high average rotation speed of the turbine, coupled with the fact that the turbine does not have a brake so it is always spinning, resulted in the high number of cycles within 1 year of testing. The degradation of the strain gages may 
have been exacerbated by blade flutter from unloaded operation of the turbine during inverter fault conditions and special test conditions. The strain gage failure is the reason Configuration B has only 78 test records.

\section{B. Inverter Torque Control}

Hysteresis in the inverter controller software for torque control resulted in some scatter in the torque-RPM curves. Fig. 3 shows a plot of torque versus RPM for Configuration C in bins of 5 RPM for 10-minute data sets. The coordinate system conforms to the IEC standard, so torque is shown as negative because the turbine rotates counterclockwise. For model validation data sets, scatter in the torque-RPM curve is undesirable, so for each configuration a limited number of data sets were taken with a fixed resistance load that reduced the torque-RPM scatter. Fig. 4 shows a plot of torque versus RPM from one 10-minute data set for Configuration $\mathrm{C}$ and a fixed resistance load.

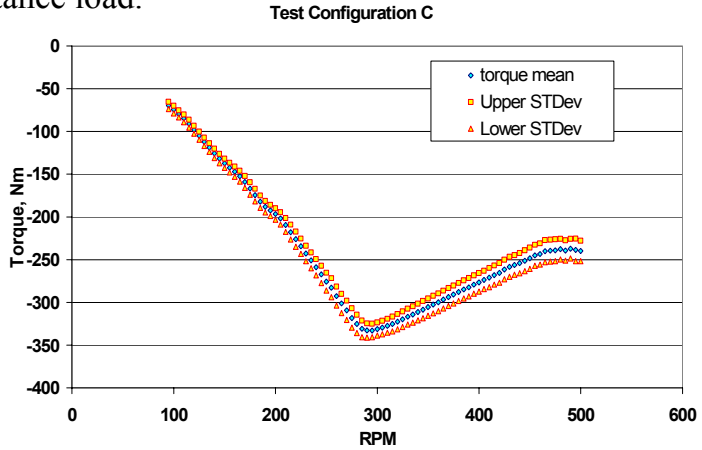

Figure 3. Torque RPM curve for Configuration $\mathrm{C}$.

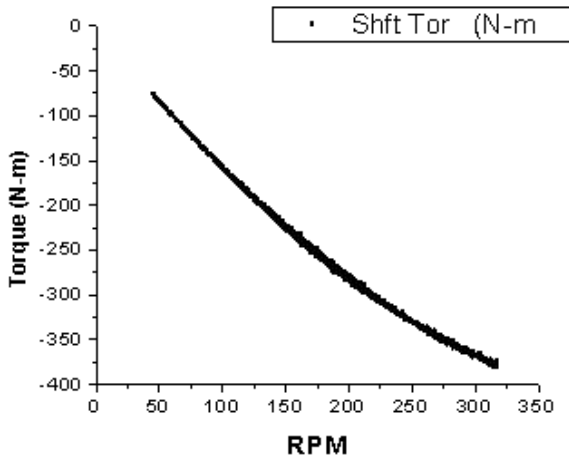

Figure 4. Torque versus RPM for fixed resistance load.

\section{Turbine Dynamics}

Power spectral densities (PSDs) were measured with the turbine operating at different rotor speeds. The PSDs showed one per revolution (1P) and 3P in all shaft and blade signals at different magnitudes. Of particular interest was the first mode tower frequency showing up in the thrust.

\section{Data Analysis}

\section{A. 10-Minute Data Sets}

Figs. 5 through 8 show scatterplots of furl, yaw rate, electrical power, and rotor speed for configuration A. The data show mean, maximum, and minimums plotted against mean wind speed. The average yaw error for Configuration $\mathrm{A}$ is between 15 and 20 degrees depending on wind speed. Because of space limitations, only scatterplots for Configuration A are shown, but comparisons between the configurations are shown later in this paper. The plots give a good overview of the operating characteristics of the SWRT: high rotor speeds, up to 500 RPM, with high maximum yaw rates and mean yaw errors.

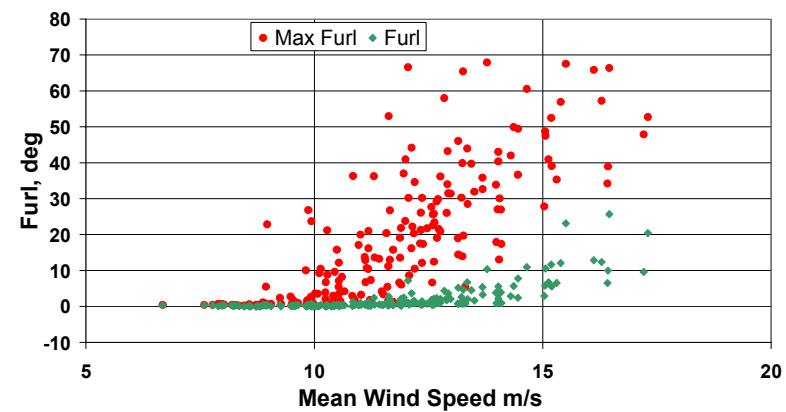

Figure 5. Furl versus mean wind speed.

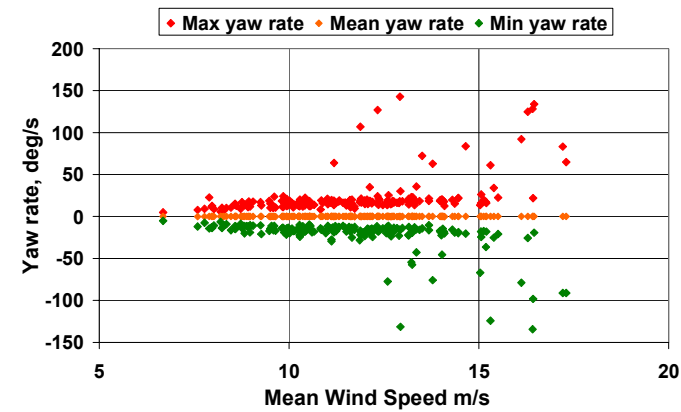

Figure 6. Yaw rate versus mean wind speed. 


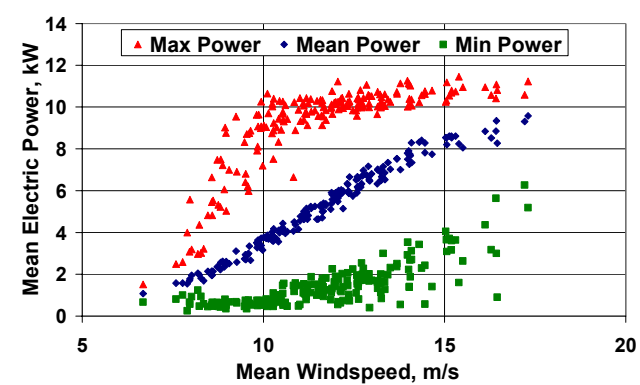

Figure 7. Electrical power versus mean wind speed.

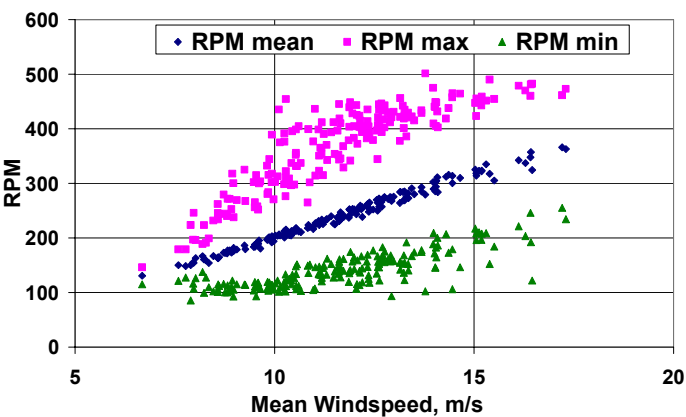

Figure 8. Rotor speed versus mean wind speed.

Figs. 9 through 11 show similar scatterplots from the same data set for shaft thrust and torque. Also shown is a plot of mean furl versus mean thrust. There is a significant amount of scatter in the plots of both mean furl versus mean wind speed and mean furl versus mean thrust.

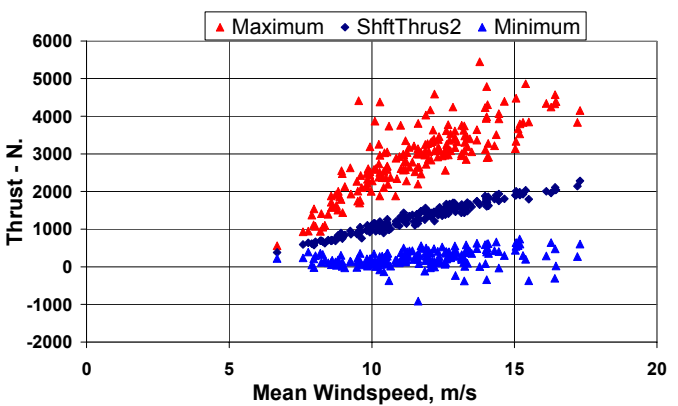

Figure 9. Thrust versus mean wind speed.

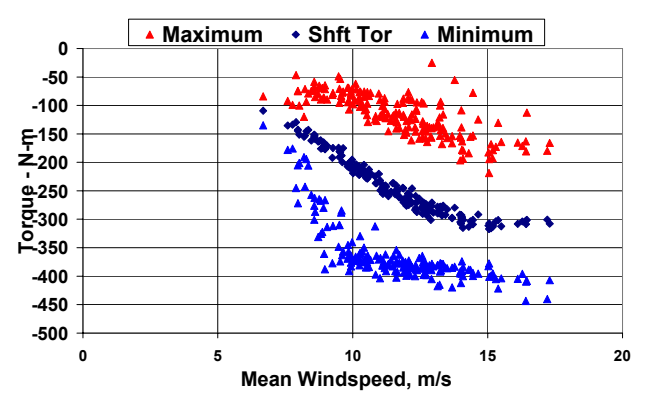

Figure 10. Torque versus mean wind speed.

\section{B. Edge-Bending Moments}

Testing results showed a large discrepancy between the sum of the three edge-bending moments when adjusted for strain gage location and compared with the torque signal. At rated wind speed, the sum of the three edge signals was $300 \%$ to $500 \%$ greater than the torque! Yet analysis of the blade signals during "slow rolls" of the rotor showed good agreement between test data and the predicted in-plane and out-of-plane blade-bending moments from gravity loads,

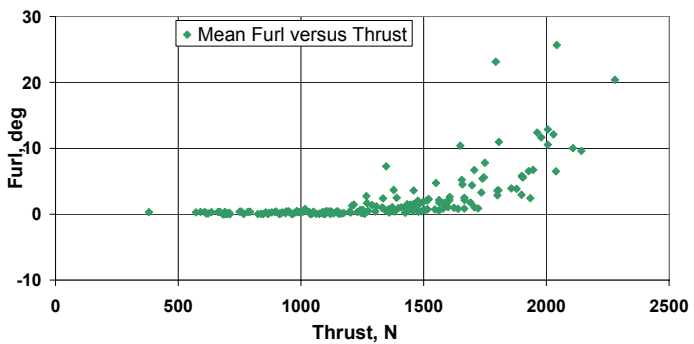

Figure 11. Furl versus thrust. which were significant because of the 8-degree shaft tilt.

The reason for the discrepancy was a small moment arm, or chordwise offset, between the blade $\mathrm{Cg}$ and the centerline of rotation and between the blade $\mathrm{Cg}$ and the edge gage neutral axis, as shown in Fig. 12. Although care was taken to align the edge gages along the neutral axis, with a complex airfoil shape there will always be some offset from the neutral axis, which creates a moment arm. As a result of the high speed of the rotor, centrifugal loading acts on this moment arm, so that the edge aerodynamic moments can be relatively small compared to the total edge-bending moment, especially at higher rotor speeds. 


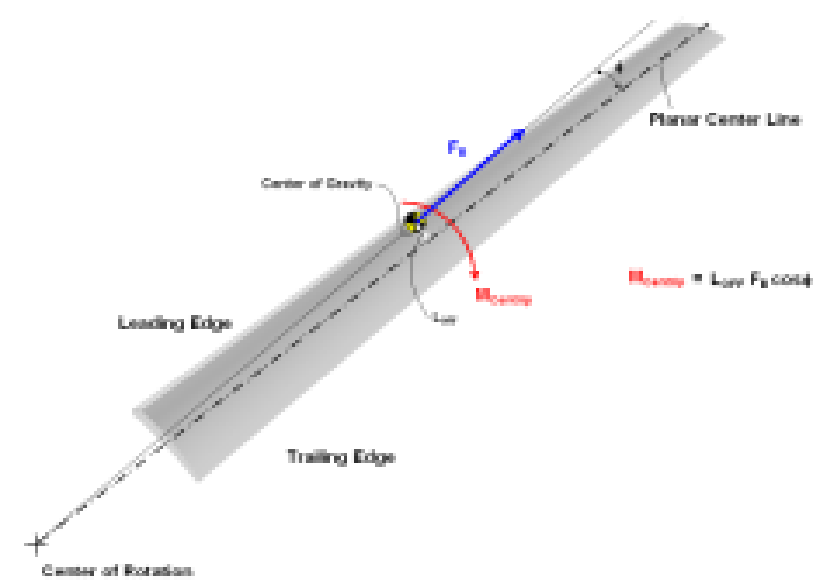

Figure 12. Moment arm between Blade $\mathrm{Cg}$ and center of rotation for edge-bending moments.

The error in the edge-bending moment from centrifugal loading caused by the offset between the edge gage neutral axis and the center of rotation is a test phenomena that has been largely overlooked to date in many test procedures. This effect will be more apparent with smaller turbines that operate at higher RPMs, but may also have some effect on larger turbines.

To calculate aerodynamic edge-bending moments, testing was conducted with the rotor unloaded and correlations between the square of rotor RPM and edge-bending moments were developed (as shown in Fig. 13) for two of the blades. This correlation was then slightly adjusted for the friction losses that are included in the unloaded torque test data by using dynamometer data of torque versus RPM for the unloaded condition.

Fig. 14 shows a scatterplot of the measured blade three-edge moment without any correction. Fig. 15 shows a scatterplot of the flap moment for blade three of the SWRT. Flap-bending response is relatively flat with wind speed and decreases at the higher wind speeds as a result of centrifugal stiffening of the blades at the high rotor speeds.

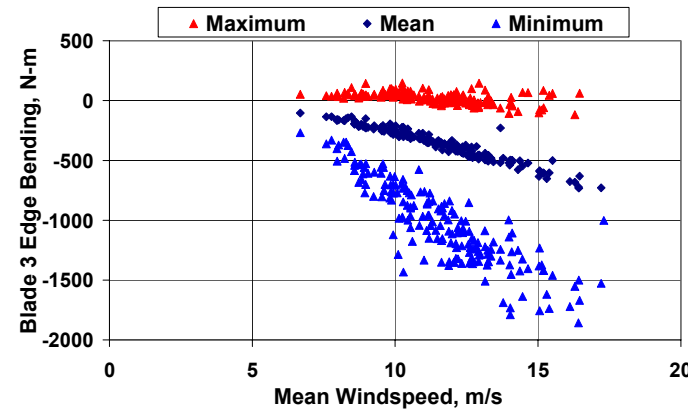

Figure 14. Edge-bending moment versus mean wind speed.

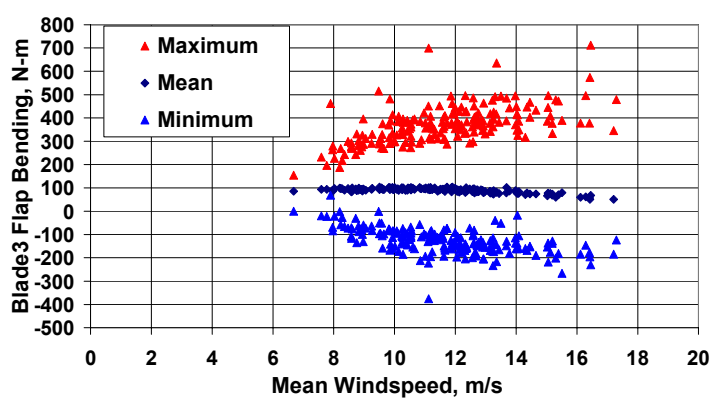

Figure 15. Flap-bending moment versus mean wind speed.

\section{Time Series Data}

Because furling is a transient phenomena, analysis of time-series data can be more useful than that of 10-minute mean data. In the time-series data, thrust and furl are often correlated, but not always. For example, the second furling event in Fig. 16 of about 14 degrees occurs when the thrust is relatively low and the rotor speed is decreasing, whereas the large furling event of 36 degrees occurs when the thrust is high and the rotor speed is increasing immediately preceding the furl, as would be expected. Yaw error changes occur rapidly and affect furl.

Calculated channels for shaft thrust and shaft 0 - and 90-degree bending moments are used to calculate the center of thrust angle (CenThrAng) and center of thrust length (CenThrLen) as follows:

CenThrAng $=$ ArcTan2 (shaft tilt moment/thrust,

shaft yaw moment/thrust)

CenThrLen $=$ Sqrt $\left((\text { shaft tilt moment } / \text { thrust })^{2}+\right.$

(shaft yaw moment/thrust) ${ }^{2}$ ) 
These equations are only valid when inertial forces can be ignored during steady state operation with negligible yaw rate; otherwise the gyroscopic forces on the shaft have too large an effect and invalidate the equations. Fig. 17 shows a time-series furling event with low yaw rate before the furling event and how CenThrLen plots in relationship to furling. Additional data analysis is needed to further evaluate using equations (1) and (2) to characterize the effect of aerodynamic thrust on furling behavior during low yaw rates.

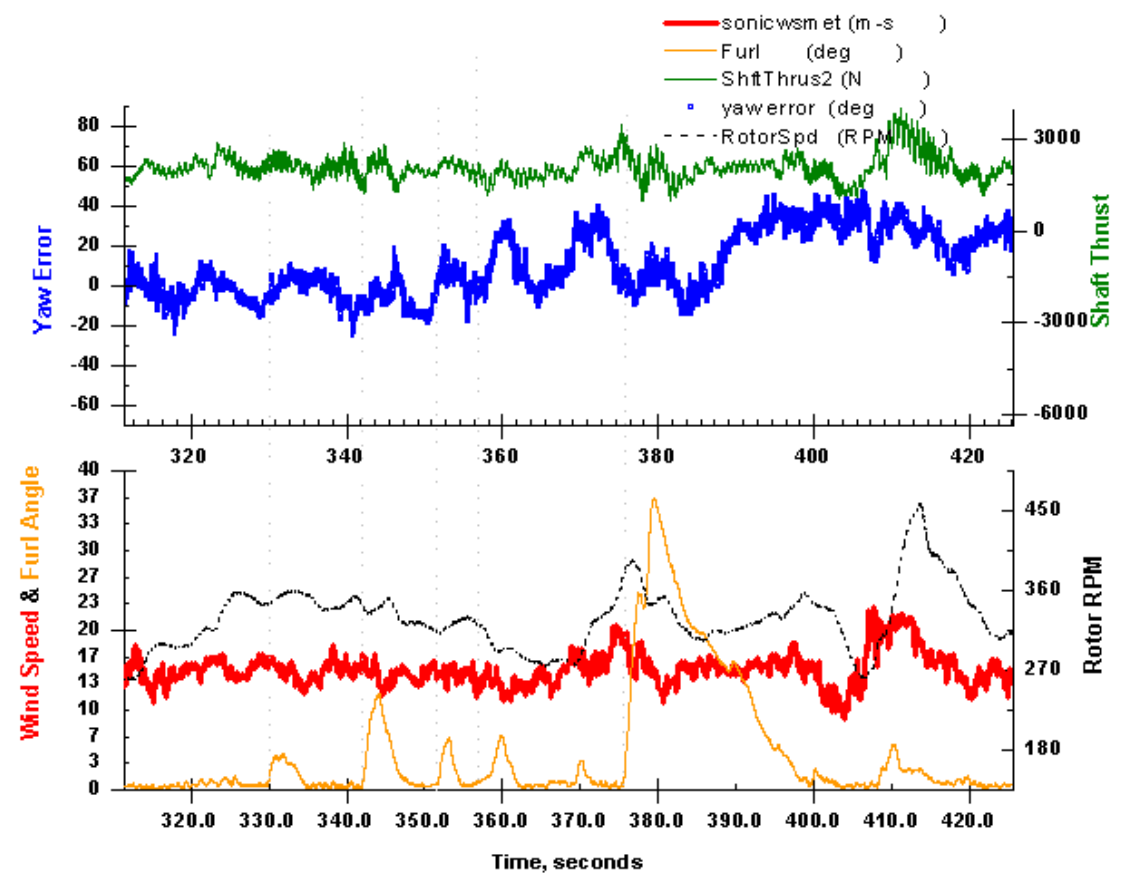

Figure 16. Time series furling events.

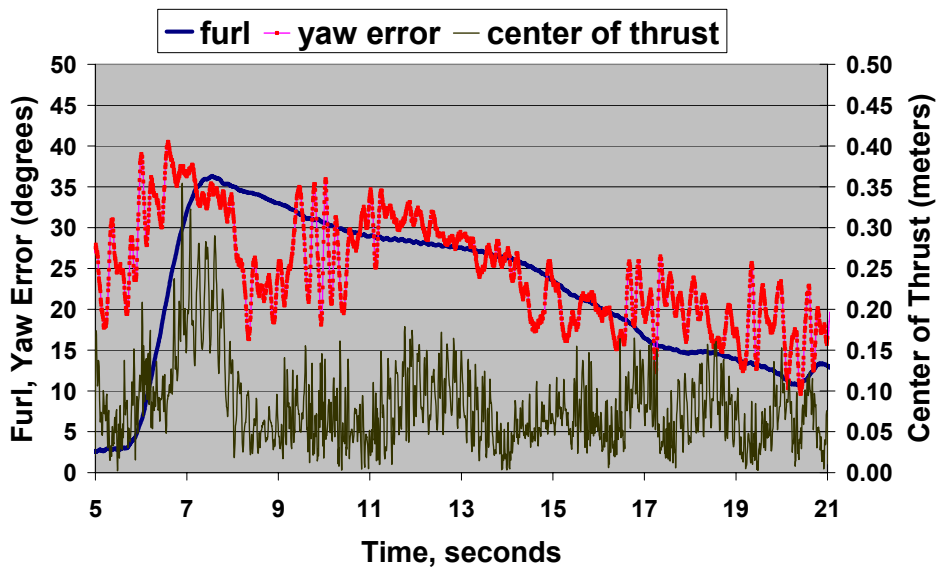

Figure 17. Furling with center of thrust. 


\section{Comparison of Data Sets}

A comparison of 10-minute scatterplots for the different configurations shows the effect of parameter changes between the configurations. Fig. 18 shows the ratio of 10-minute mean meteorological tower wind speeds to tail wind speeds for Configuration A and C plotted against wind speed. The greater solidity (about 16\% higher) and 33\% greater swept area of Configuration $\mathrm{C}$ results in a significantly reduced tail wind speed as compared to Configuration A. Because the data are for a very narrow power coefficient $(\mathrm{Cp})$ range, the ratios for a given configuration do not change much with wind speed until the higher wind speeds where the turbine is furled a large percentage of the time and the sonic tail anemometer is partially out of the wake. Rotor speeds for Configuration $\mathrm{C}$ are about 25 RPM greater than that of A and B until furling.

Fig. 19 shows a comparison of 10-minute mean furling versus wind speed for configuration $\mathrm{A}, \mathrm{B}$, and $\mathrm{C}$. The data show only those data points with furl greater than 1.5 degrees and is fitted with a third-order polynomial resulting from the high degree of scatter. The data show that Configuration $\mathrm{C}$ furls the most, predominantly because of the higher thrust resulting from the higher solidity of the

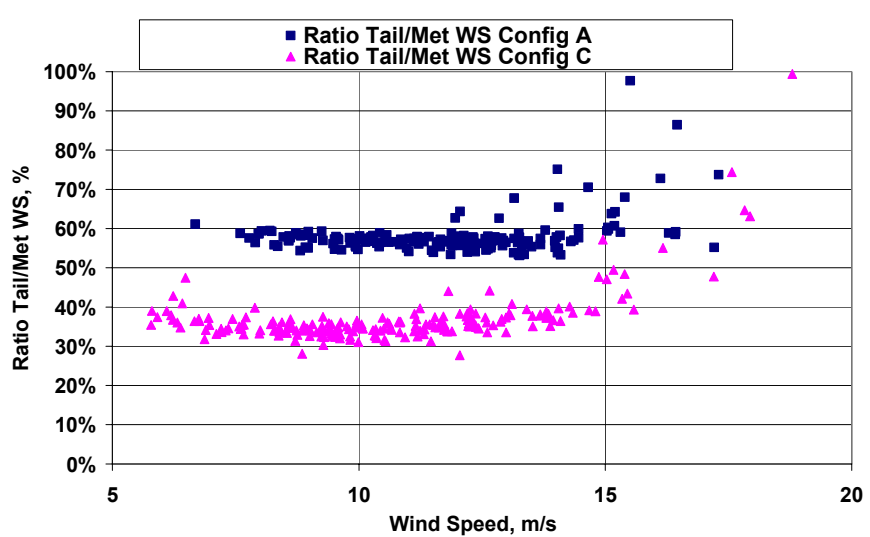

Figure 18. Ratio of tail/met wind speed versus wind speed.

blades and larger swept area, followed by A with a 4degree shim and lower solidity and shorter blades, and then $\mathrm{B}$ with the same blades as A, but without the shim.

Figs. 20-22 show data for thrust, shaft-yaw moment, and shaft-tilt moment for the different configurations. Configuration $\mathrm{C}$ has a significantly higher thrust and also higher yaw and tilt moments. The data for Configurations $\mathrm{A}$ and $\mathrm{B}$ are similar and hard to differentiate. (The coordinate system conforms to the IEC standard, so the $\mathrm{x}$ axis is parallel to the main shaft and positive downwind; the $\mathrm{z}$-axis is perpendicular to the main shaft and positive up; and $x-y-z$ form a right-hand system. The shaft tilt moment (My) is the moment about the y-axis and shaft yaw moment (Mz) is the moment about the z-axis. Note that the overhang moment for shaft tilt is not included in the data.)

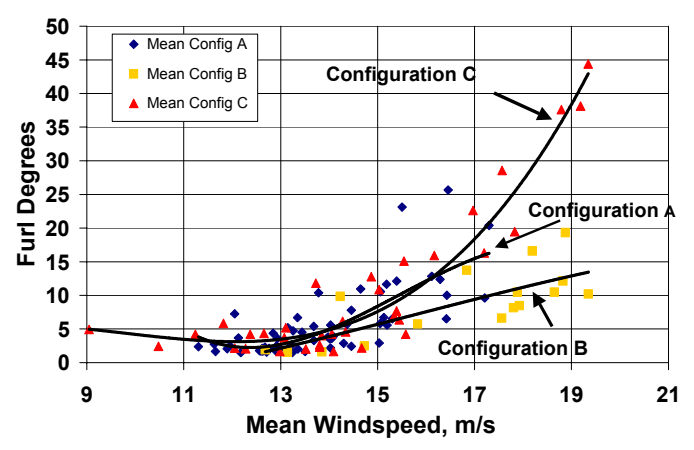

Figure 19. Furl versus wind speed for different configurations.

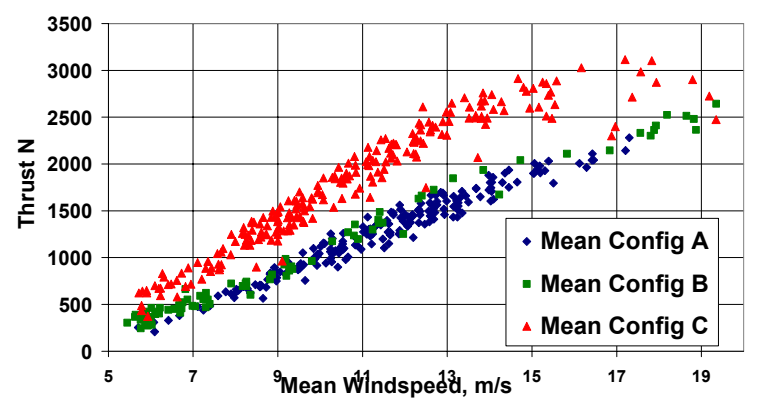

Figure 20. Shaft thrust versus wind 


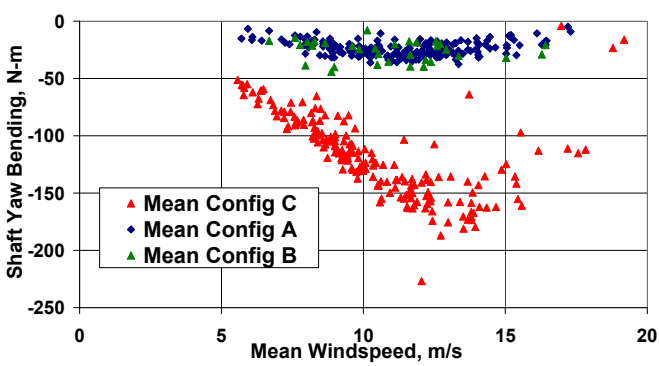

Figure 21. Shaft yaw moment versus wind speed for different configurations.

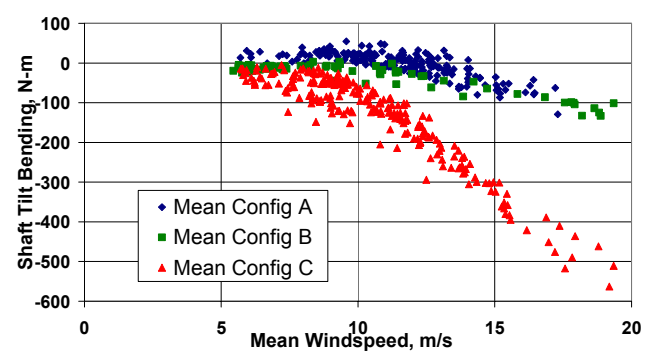

Figure 22. Shaft tilt moment versus wind speed for different configurations.

\section{Correlation Between Inflow and Furling}

\section{A. Inflow Data Processing Equations}

In recent years, significant work has been conducted showing the relationship between inflow parameters and fatigue loads for wind turbines [7, 8]. To better understand the relationship between coherent or organized turbulence and the potential impact on furling, calculated channels were developed for several different inflow parameters based on the data measured from the sonic anemometer on the meteorological tower.

The following inflow parameters were calculated for each data set.

$u_{f_{H}}\left(t_{i}\right)=\left|u_{p_{1}}\left(t_{i}\right) \cos \beta+u_{p_{2}}\left(t_{i}\right) \sin \beta\right|(\mathbf{3}) u_{f_{1}}\left(t_{i}\right)=u_{f_{H}}\left(t_{i}\right) \cos \phi+u_{p_{3}}\left(t_{i}\right) \sin \phi$

$u_{f_{2}}\left(t_{i}\right)=-u_{p_{1}}\left(t_{i}\right) \sin \beta+u_{p_{2}}\left(t_{i}\right) \cos \beta$

$u_{f_{3}}\left(t_{i}\right)=-u_{p_{H}}\left(t_{i}\right) \sin \phi+u_{p_{3}}\left(t_{i}\right) \cos \phi$

where $u_{f_{1}}, u_{f_{2}}$, and $u_{f_{3}}$ are wind vectors rotated from those measured in the sonic probe coordinate system $\left(p_{1,2,3}\right)$ to ones aligned with the flow $\left(f_{1,2,3}\right)$ and in the direction of the mean shearing stress, and

$\beta=\arctan \left(\overline{u_{p_{2}}} / \overline{u_{p_{1}}}\right)$

$\phi=\arctan \left(\overline{u_{p_{3}}} / \overline{u_{p_{H}}}\right)$

and $u_{p_{1}}$ and $u_{p_{2}}$ are the horizontal velocity components measured along the sonic probe $\mathrm{x}$-axis and y-axis, respectively, and $u_{p_{3}}$ is the vertical velocity component measured along the sonic probe z-axis. The turbulent or fluctuating (i.e., zero-mean) component velocities (i.e., longitudinal, transverse or crosswind, and vertical velocities) for which only the longitudinal (i.e., streamwise) component aligned with the flow vector $u_{f_{1}}$ has a non-zero mean, are defined as

$u^{\prime}\left(t_{i}\right)=u_{f_{1}}\left(t_{i}\right)-\overline{u_{f_{1}}}=u_{f_{1}}\left(t_{i}\right)-\frac{1}{N} \sum_{i=1}^{N} u_{f_{1}}\left(t_{i}\right)$ (9)

$v^{\prime}\left(t_{i}\right)=u_{f_{2}}\left(t_{i}\right)$

$w^{\prime}\left(t_{i}\right)=u_{f_{3}}\left(t_{i}\right)$

The turbulent Reynolds stress components are

$u^{\prime} w^{\prime}\left(t_{i}\right)=u^{\prime}\left(t_{i}\right) \cdot w^{\prime}\left(t_{i}\right)$

$u^{\prime} v^{\prime}\left(t_{i}\right)=u^{\prime}\left(t_{i}\right) \cdot v^{\prime}\left(t_{i}\right)$

$v^{\prime} w^{\prime}\left(t_{i}\right)=v^{\prime}\left(t_{i}\right) \cdot w^{\prime}\left(t_{i}\right)$ 
and the mean shearing stress or friction velocity is defined as

$\mathrm{u}^{*}=\sqrt{\left|\overline{u^{\prime} w^{\prime}}\right|}$

and the turbulence kinetic energy (TKE) is

$\mathrm{TKE}=0.5 *\left[\left(\mathrm{u}^{\prime}\right)^{2}+\left(\mathrm{v}^{\prime}\right)^{2}+\left(\mathrm{w}^{\prime}\right)^{2}\right]$

and coherent TKE $($ CoTKE $)=0.5 * \operatorname{SQRT}\left[\left(u^{\prime} w^{\prime}\right)^{2}+\left(u^{\prime} v^{\prime}\right)^{2}\right.$.

$\left.+\left(\mathrm{v}^{\prime} \mathrm{w}^{\prime}\right)^{2} \cdot\right]$.

In addition to the inflow parameters listed in equations 3 through 17, the gradient Richardson number (Ri) for a height of $2-80 \mathrm{~m}$ was obtained from a meteorological tower at the NWTC and included in the data sets for the SWRT. The Richardson number can be useful in explaining turbulence because it represents the ratio of turbulence generation by buoyancy (i.e., thermal) to wind shear (i.e., mechanical) forces. A negative value of $\mathrm{Ri}$ represents unstable or convective conditions, a value of zero represents neutral, and positive values signify a stable flow.

A correlation analysis was conducted to determine whether inflow parameters have a significant impact on furling. Using the inflow parameters described in equations 9 through 17, a single variable correlation analysis was done for each test configuration, which yielded a list of variables that are highly correlated to furl angle. A multivariate correlation was then done on each test configuration to determine how sensitive the variables are to furl. Space limitations in this paper prevent presentation of all the detailed results, but a summary of the multivariate regression is provided below.

Configuration A: The highest correlation (correlation coefficient, $r^{2}$, is 0.65 ) was obtained between furl and the combination of coherent turbulent kinetic energy (CoTKE), standard deviation of the vertical wind component of the inflow $\left(w^{\prime}\right)$, and mean wind speed.

Configuration B: The highest correlation (correlation coefficient, $r^{2}$, is 0.72 ) was obtained between furl and the combination of max CoTKE, max wind speed, and wind speed.

Configuration $\mathrm{C}$ : The highest correlation (correlation coefficient, $r^{2}$, is 0.79) was obtained between furl and $w^{\prime}$, local friction velocity $\mathrm{u}^{*}$, wind speed, and rotor speed. The introduction of rotor speed made the correlation coefficient change dramatically and, even though it is a machine variable, it was left in. When it was taken out, the $r^{2}$ value went down significantly.

Configuration $\mathrm{B}$, the configuration that is hardest to furl, is most sensitive to the maximum wind speed and maximum CoTKE. The same configuration without the shim (i.e., A) furls easier and is sensitive to the mean CoTKE and mean wind speed, as well as $w^{\prime}$. Configuration $\mathrm{C}$, the easiest to furl configuration, is not sensitive to CoTKE.

Fig. 23 shows a plots of furling versus wind speed, $w^{\prime}$, and CoTKE; Fig. 24 shows a plot of furling versus Ri for Configuration A. Note that the maximum furling occurs at
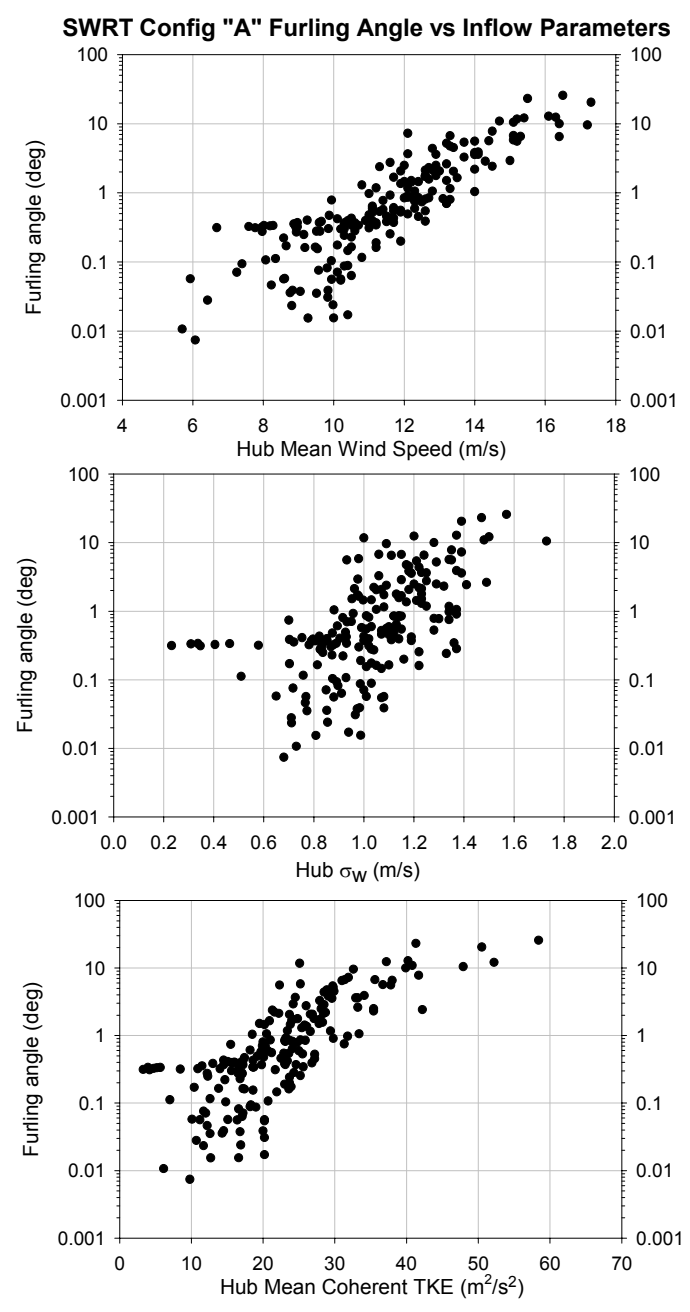

Figure 23. Furling and inflow.

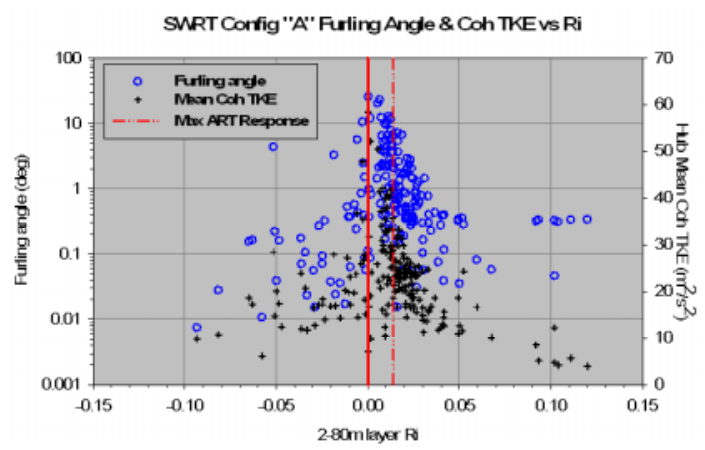

Figure 24. Furling versus Richardson Number. 


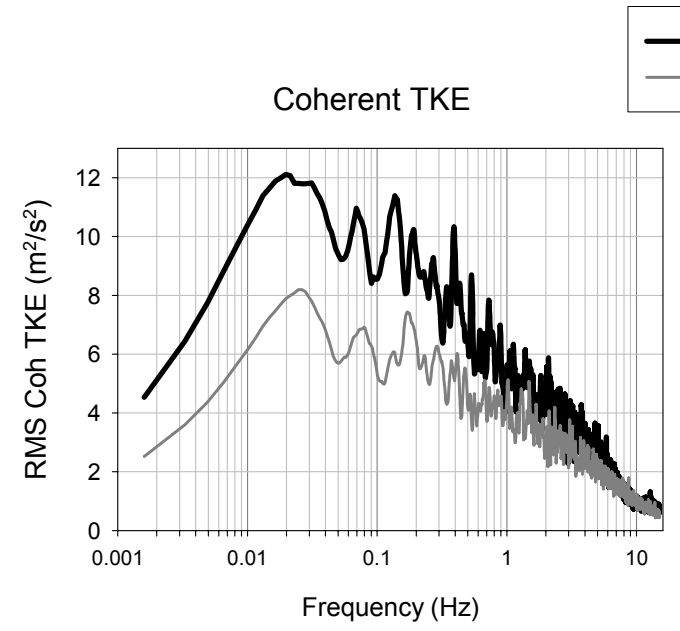

Vertical Gust Velocity Variance
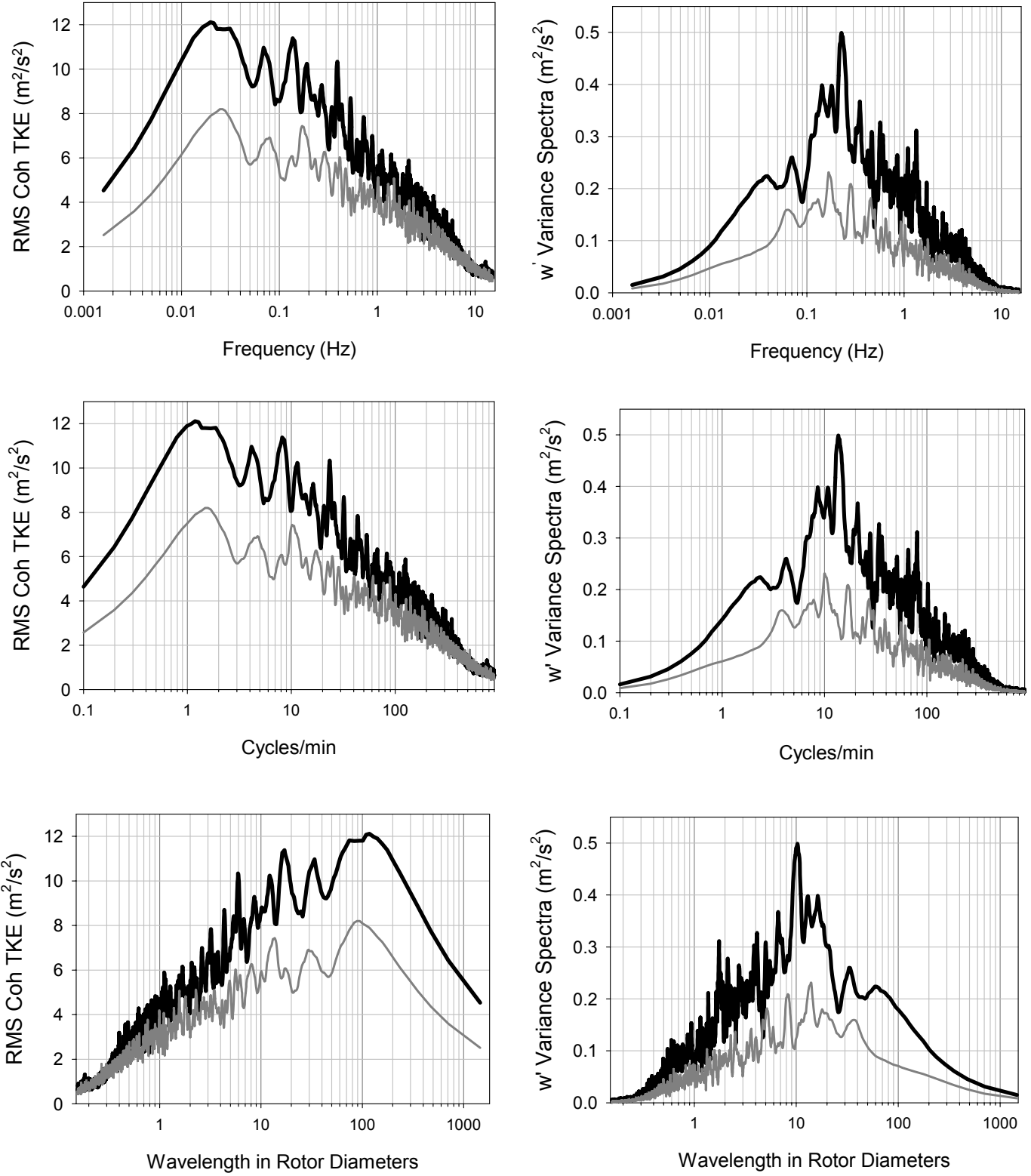

Figure 25. CoTKE and vertical gust variance for two files with same wind speed and different furl. 
about an Ri of 0.13. This is indicative of a site with a lot of coherent turbulence. The maximum load response from another test turbine at the NWTC, the ART, is also shown on the graph for comparison.

As a last indicator of the importance of looking at inflow when analyzing furling, Fig. 25 shows plots of the RMS CoTKE and RMS $w^{\prime}$ (vertical gust velocity variance) versus frequency, cycles/minute, and wavelength in rotor diameters. The data are for two different time series plots from Configuration A with a wind speed of $14 \mathrm{~m} / \mathrm{s}$ for both, but different turbulence parameters. In one file, the mean 10-minute furl is zero, whereas the other is 4 degrees. The mean wind direction for each file is within one degree of each other. CoTKE and $w^{\prime}$ were chosen as the variables to plot based on the correlation analysis. Mean wind speed, the other highly correlated variable, is the same for both files. The data show the effect of coherent turbulence and $w^{\prime}$ on furling. The data also show a range of time for when the maximum energy is occurring and an indication of the wavelength of the maximum CoTKE and $w^{\prime}$ in relation to the rotor diameter (this was calculated by dividing by the mean wind speed).

\section{Conclusions}

The SWRT test has provided modelers with unique data sets to validate the FAST aeroelastic simulation model with furling and to understand small wind turbine dynamics and loads. The test resulted in a better understanding of aerodynamic and inertia edge-bending moment measurements. Analysis of statistical and time-series data shows the complex interaction of thrust, center of thrust, yaw rate, RPM, and how these variables relate to furl. Finally, it is shown that turbine furling can be affected by the vertical velocity gradient and the coherent turbulence.

Future SWRT data analysis will include further analysis of the shaft thrust and bending loads to determine the usefulness of center of thrust calculations in regard to inertial and aerodynamic forces, more analysis of time-series data, additional comparisons of FAST model results with SWRT data for all configurations, and further examination of the effect of inflow on furling.

\section{Acknowledgments}

The authors thank everyone who helped with this work, including Mark Meadors of NREL, whose invaluable assistance with the testing made this paper possible; Todd Hanley of Bergey Windpower and Charles Newcomb of NREL for their help in the design of the SWRT; Marshall Buhl of NREL, who assisted in data manipulation and answered our CRUNCH and GPP questions with patience; Neil Kelley of NREL, who helped us with the inflow analysis; Craig Hansen of Windward Engineering, who provided insights into furling and helpful analysis of the SWRT data as well as comparisons of the SWRT data to ADAMs and FAST modeling results; Jason Jonkman of NREL for his development of the FAST furling model; and to Ruth Baranowski of NREL for making this paper much more readable.

\section{References}

${ }^{1}$ Jonkman, J.M., and Hansen, A.C., "Development and Validation of an Aeroelastic Model of a Small Furling Wind Turbine," Collection of the 2005 ASME Wind Energy Symposium Technical Papers Presented at the $43^{\text {rd }}$ AIAA Aerospace Sciences Meeting and Exhibit, 10-13 January 2005, Reno, NV, Washington, D.C.: American Institute of Aeronautics and Astronautics, January 2005, NREL/CP-500-36776.

${ }^{2}$ Jonkman, J.M., Buhl, M.L., (March 2004). “FAST User’s Guide”. NREL/EL-500-29798. Golden, CO: National Renewable Energy Laboratory, 105 pp.

${ }^{3}$ Jonkman, J.M., Buhl, M.L., (January 2004). "New Developments for the NWTC's FAST Aeroelastic HAWT Simulator," Collection of the 2004 ASME Wind Energy Symposium Technical Papers Presented at the $42^{r d}$ AIAA Aerospace Sciences Meeting and Exhibit, 5-8 January 2004, Reno, NV, Washington, D.C.: American Institute of Aeronautics and Astronautics, pp. 181-191; NREL/CP-500-35077.

${ }^{4}$ Davis, Dean A., Hansen, A. Craig, and Laino, David J. (2003). "Estimates of Maximum Design Loads for a Whisper H40 using Extrapolation Methods." Proceedings of the Windpower 2003 Conference, 18-21 May, 2003, Austin, TX. Iwashington D.C.: American Wind Energy Association; session 4C. 
${ }^{5}$ NWTC Furling (Furling Workshop by Buhl, M.L.,). http://wind.nrel.gov/Furling/workshop.html. Last modified November 21, 2002; accessed August 19, 2004.

${ }^{6}$ Eggers, A.J., Chaney, K., Holley, W.E., and Ashley, H. (2000). "Modeling of Yawing and Furling Behavior of Small Wind Turbines," Collection of the 2000 ASME Wind Energy Symposium Technical Papers Presented at the $38^{\text {th }}$ AIAA Aerospace Sciences Meeting and Exhibit, 5-8 January 2000, Reno, NV, Washington, D.C.: American Institute of Aeronautics and Astronautics.

${ }^{7}$ Kelley, N.; Shirazi, M.; Jager, D.; Wilde, S.; Adams, J.; Buhl, M.; Sullivan, P.; Patton, E., "Lamar Low-Level Jet Program Interim Report," NREL TP-500-34593, 2004.

${ }^{8}$ Sutherland, H. J.; Kelley, N. D.; Hand, M. M. (2003). Inflow and Fatigue Response of the NWTC Advanced Research Turbine. Collection of the 2003 ASME Wind Energy Symposium Technical Papers at the 41st AIAA Aerospace Sciences Meeting and Exhibit, 6-9 January 2003, Reno, Nevada. New York: American Institute of Aeronautics and Astronautics, Inc. (AIAA) and American Society of Mechanical Engineers (ASME); pp. 214-224; NREL Report No. CP-500-35270. 


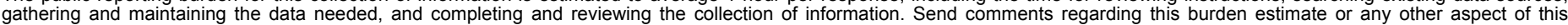

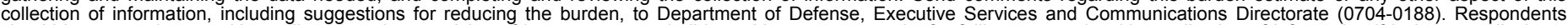

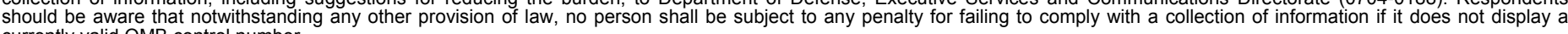

PLEASE DO NOT RETURN YOUR FORM TO THE ABOVE ORGANIZATION.

\section{REPORT DATE (DD-MM-YYYY) \\ November 2004}

4. TITLE AND SUBTITLE

Analysis and Comparison of Test Results from the Small Wind

Research Turbine Test Project: Preprint
3. DATES COVERED (From - To)

5a. CONTRACT NUMBER

DE-AC36-99-G010337

5b. GRANT NUMBER

5c. PROGRAM ELEMENT NUMBER

5d. PROJECT NUMBER

NREL/CP-500-36891

5e. TASK NUMBER

WER4 3304

5f. WORK UNIT NUMBER
7. PERFORMING ORGANIZATION NAME(S) AND ADDRESS(ES)

National Renewable Energy Laboratory

1617 Cole Blvd.

Golden, CO 80401-3393

9. SPONSORING/MONITORING AGENCY NAME(S) AND ADDRESS(ES)
8. PERFORMING ORGANIZATION REPORT NUMBER

NREL/CP-500-36891

10. SPONSOR/MONITOR'S ACRONYM(S) NREL

11. SPONSORING/MONITORING AGENCY REPORT NUMBER

\section{DISTRIBUTION AVAILABILITY STATEMENT}

National Technical Information Service

U.S. Department of Commerce

5285 Port Royal Road

Springfield, VA 22161

13. SUPPLEMENTARY NOTES

\section{ABSTRACT (Maximum 200 Words)}

Most small wind turbines furl (yaw or tilt out of the wind) as a means of limiting power and rotor speeds in high winds. The Small Wind Research Turbine (SWRT) testing project was initiated in 2003 with the goal of better characterizing both small wind turbine loads (including thrust) and dynamic behavior, specifically as they relate to furling. The main purpose of the testing was to produce high-quality data sets for model development and validation and to help the wind industry further their understanding of small wind turbine behavior. Testing was conducted on a modified Bergey Excel 10-kW wind turbine. A special shaft sensor was designed to measure shaft loads including thrust, torque, and shaft bending. Analysis of 10-minute mean data showed a strong correlation between furling and center of thrust location, as calculated from the shaft-bending and thrust measurements. Data were collected for three different turbine configurations that included a change in the lateral furling offset and the blades. An analysis of inflow conditions indicated that organized atmospheric turbulence had some impact on furling.

\section{SUBJECT TERMS}

wind energy; wind turbine; small wind research turbine project; SWRT; Bergey Excel

\begin{tabular}{|c|c|c|}
\hline 16. SECURIT) & CLASSIFICATI & N OF: \\
\hline $\begin{array}{l}\text { a. REPORT } \\
\text { Unclassified }\end{array}$ & $\begin{array}{l}\text { b. ABSTRACT } \\
\text { Unclassified }\end{array}$ & $\begin{array}{l}\text { c. THIS PAGE } \\
\text { Unclassified }\end{array}$ \\
\hline
\end{tabular}

19a. NAME OF RESPONSIBLE PERSON

19b. TELEPONE NUMBER (Include area code) 